NSL 03777

\title{
CHANGES IN EXTRACELLULAR PH DURING ELECTRICAL STIMULATION OF ISOLATED RAT VAGUS NERVE
}

\author{
W. ENDRES ${ }^{1}$. P. GRAFE ${ }^{1 *}$, H. BOSTOCK ${ }^{2}$ and G. TEN BRUGGENCATE'
}

'Department of Physiology, University of Munich, Pettenkoferstr. 12, D-8000 München 2 (F.R.G.), and 'Institute of Neurology, Queen Square, London WCIN 3 BG (U.K.)

(Received October 16th, 1985; Revised version received November 15th, 1985; Accepted November $181 \mathrm{~h}$. 1985)

Key w'ords: pH - vagus nerve - ion-sensitive micro-electrode - ouabain - excitability - rat

Double-barrelled $\mathrm{pH}$-sensitive micro-electrodes were used to record changes of extracellular $\mathrm{pH}$ during repetitive stimulation of isolated rat vagus nerves. It was found that a small initial alkaline shilt was followed by a prolonged acidification. The acidification was correlated in time with the poststimulus undershoot of the extracellular $\mathrm{K}^{+}$activity and with the recovery phase of the nerve conduction velocity. In the presence of ouabain, the acid component of the $\mathrm{pH}$ change was completely abolished (indicating a metabolic origin), whereas the alkaline component remained unaltered. These $\mathrm{pH}$ changes were too small to make a significant contribution to the activity-related changes in conduction velocity of the vagal $C$ fibres.

Activity in central and peripheral nerve fibres is accompanied by alterations of their excitability. The possible contribution of changes in extracellular $\mathrm{pH}\left(\mathrm{pH}_{\mathrm{c}}\right)$ to modifications of axonal excitability has, however, remained a matter of speculation. A recently designed neutral carrier-based hydrogen ion-selective micro-electrode [1] has now enabled us to obtain information about activity-related $\mathrm{pH}$ changes in rat ventral roots and vagus nerves. Whereas activity of the myelinated nerve fibres in the spinal roots was not accompanied by a detectable (i.e. bigger than $0.01 \mathrm{pH}$ units) rise or decrease of $\mathrm{pH}_{\mathrm{e}}$ [4], unmyelinated nerve fibres in rat vagus nerves did show such alterations. The data from the latter preparation are described in the present paper.

Cervical vagus nerves were isolated from urethane- or thiogenal-anesthetized rats and the connective tissue sheath was removed. The experiments were performed in a small temperature-controlled perspex bath $\left(25-30^{\circ} \mathrm{C}\right)$ through which a solution of the following composition was pumped (in $\mathrm{mM}$ ): $\mathrm{NaCl} 118, \mathrm{KCl} 3, \mathrm{CaCl}_{2} 1.5$. $\mathrm{NaHCO}_{3} 25, \mathrm{NaH}_{2} \mathrm{PO}_{4} 1.2, \mathrm{MgCl}_{2} 1$, glucose 10 . The free nerve ends were drawn into a pair of glass suction electrodes which allowed stimulation and recording of compound potentials. Stimulus strength was adjusted above the maximal amplitude of the C-fibre component. Double-barrelled pH-(Fluka 82500) and $\mathrm{K}^{+}$-sensitive (Corn-

\footnotetext{
*Author for correspondence.
} 


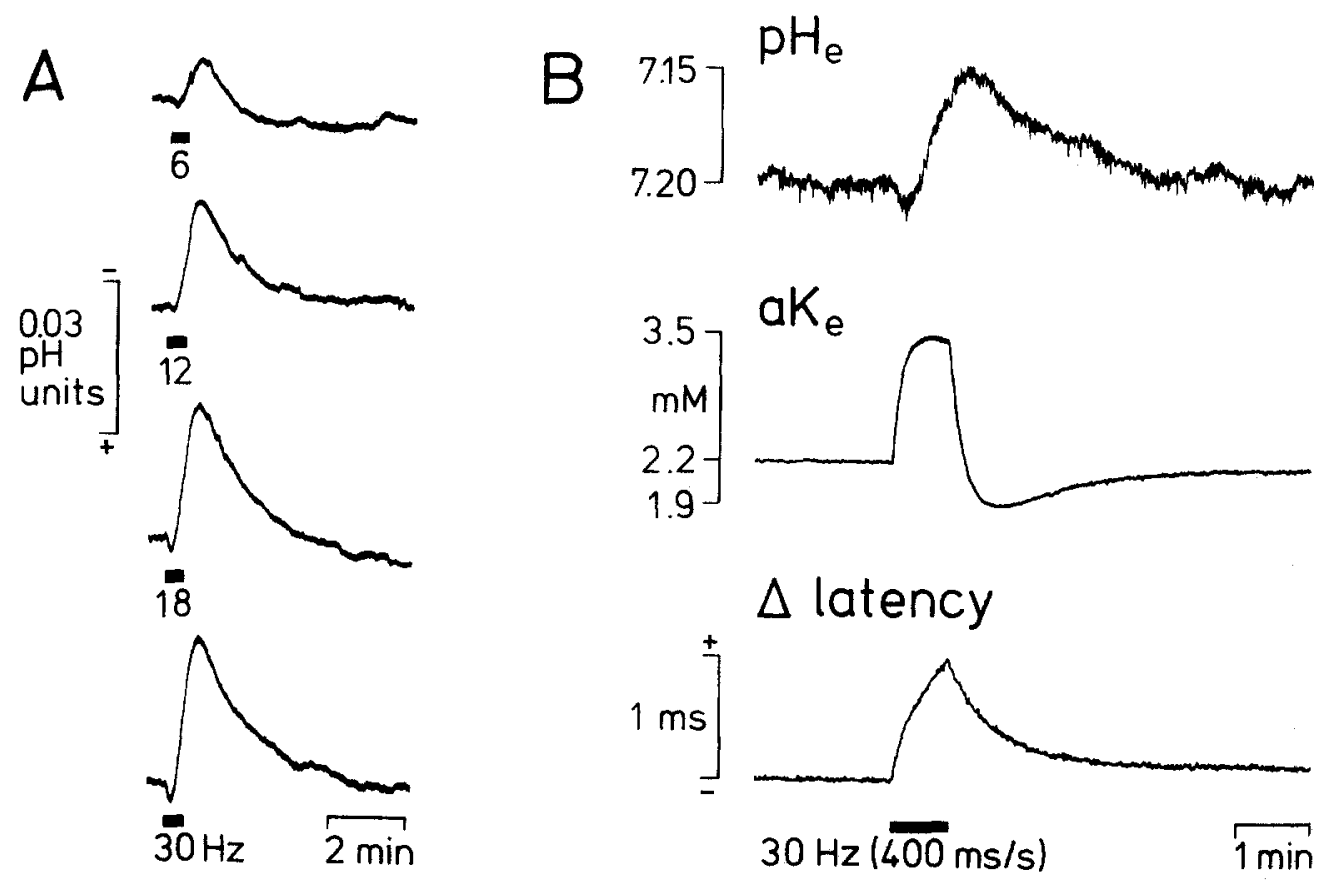

Fig. 1. Changes in $\mathrm{pH}_{\mathrm{e}}$ during electrical stimulation of rat vagus nerve. (A) shows an experiment in which stimulus trains of different frequencies and constant duration were used. (B) compares the changes in $\mathrm{pH}_{\mathrm{c}}$ with the changes in $\mathrm{aK}_{\mathrm{e}}$ and with the latency of the $\mathrm{C}$-fibre compound action potential recorded concurrently. The recording of the latency required intermittent trains of stimuli: trains of $30 \mathrm{~Hz}$ frequency and $400 \mathrm{~ms}$ duration were applied every second for a period of $60 \mathrm{~s}$ (mean rate $12 \mathrm{~Hz}$ ). The latency recorded was of the first action potential in each $400 \mathrm{~ms}$ train.

ing 477317) micro-electrodes were built as described elsewhere [7] (tips broken under visual control to a diameter of $1-2 \mu \mathrm{m})$. $\mathrm{pH}$ was calculated by means of calibration curves obtained for each electrode with 3 different standard $\mathrm{pH}$ solutions. An activity coefficient of 0.74 was used to calculate the extracellular potassium activity $\left(\mathrm{aK}_{\mathrm{e}}\right)$. The latency of the compound C-fibre potential was monitored continuously by means of an analog circuit [4].

Fig. IA shows activity-related $\mathrm{pH}_{\mathrm{e}}$ changes in an isolated rat vagus nerve during stimulation trains of different frequencies. The typical observation was a biphasic $\mathrm{pH}$ change, consisting of an alkaline shift at the onset of the stimulation period followed, after about $20 \mathrm{~s}$, by a prolonged acidification. The maximum changes of $\mathrm{pH}_{\mathrm{e}}$ during stimulation trains of $30 \mathrm{~Hz}, 30 \mathrm{~s}$ duration, were $0.02 \mathrm{pH}$ units in the alkaline direction and $0.05 \mathrm{pH}$ units in the acid direction. The acid phase had its maximum after the end of the stimulation period and lasted up to several minutes. Such an alkaline-acid sequence of activity-related $\mathrm{pH}_{\mathrm{e}}$ changes has been previously described in mammalian cortex during stimulation, spreading depression and cerebral ischemia $[8,9,13]$, and also in working skeletal muscle $[6,12]$. Fig. $1 \mathrm{~B}$ compares the changes in $\mathrm{pH}_{\mathrm{e}}$ to those in $\mathrm{aK}_{\mathrm{c}}$ and the latency of the $\mathrm{C}$-fibre compound potential. The acidification decayed with a similar time-course to the $\mathrm{aK}_{\mathrm{e}}$ undershoot and the recovery of the 

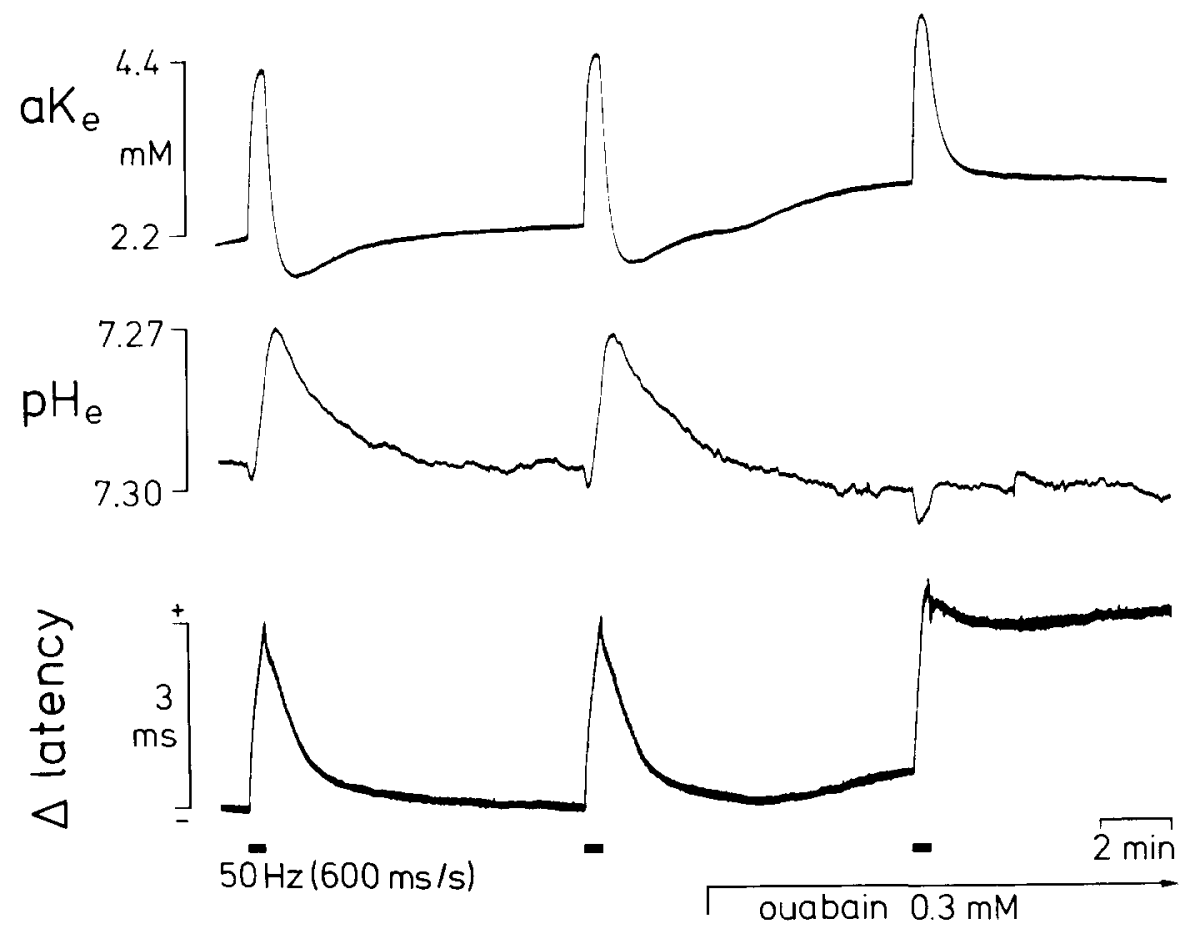

Fig. 2. Effects of ouabain on stimulus-induced changes in $\mathrm{aK}_{\mathrm{e}}, \mathrm{pH}_{\mathrm{e}}$ and latency of the C-fibre compound action potential. After 2 stimulus trains in normal bathing solution (intermittent stimulation used, as described in Fig. 1), the vagus nerve was stimulated again in the presence of ouabain. Note that ouabain blocked both the poststimulus a $\mathrm{K}_{\mathrm{c}}$ undershoot and the recovery from the increase in latency. and it also completely abolished the acidification.

latency. Previous data have shown that $a \mathrm{~K}_{\mathrm{e}}$ undershoot and changes in latency are related to the time it takes the $\mathrm{Na}^{+}$-pump to decrease the intracellular $\mathrm{Na}^{+}$concentration to its baseline level $[3-5,10]$. It seemed likely, therefore, that the acidification was also metabolic in origin.

To test for a metabolic source of the acidification we used ouabain to block the $\mathrm{Na}^{+}, \mathrm{K}^{+}$-pump (Fig. 2). In the presence of ouabain, nerve activity resulted in a rise of $\mathrm{aK}_{\mathrm{c}}$, an increase in latency and an initial alkaline shift. All 3 effects were quantitatively similar to those in the normal bathing solution. On the other hand, ouabain blocked both the poststimulus $\mathrm{aK}_{\mathrm{c}}$ undershoot and the recovery from the increase in latency, and it also completely abolished the acidification. Replacement of $\mathrm{NaCl}$ by equimolar $\mathrm{LiCl}$ to prevent activation of the $\mathrm{Na}^{+}$-pump had similar effects. These observations indicate, in accordance with previous interpretations [8, 9, 12], that inhibition of the energy consumption by the $\mathrm{Na}^{+}$-pump and the subsequent lactate production are responsible for the absence of the acid release. The experiment also reveals the importance of the rise in intracellular $\mathrm{Na}^{+}$to the change in latency of $\mathrm{C}$-fibres. This is in contrast to myelinated nerve fibres, in which the membrane hyperpolarization due to electrogenic $\mathrm{Na}^{+}$pumping, and not the $\mathrm{Na}^{+}$influx itself, seems to be the factor underlying the increase in latency [4]. 
The origin of the alkaline shift is more obscure. Our results enable us to exclude two of the mechanisms previously proposed for this phenomenon. The alkaline shift can neither be related to an increased $\mathrm{CO}_{2}$ washout due to enhanced blood flow [13] (since it is clearly visible in an isolated preparation), nor be due to the splitting of intracellular phosphocreatine [12] (since ouabain should have also blocked this process $[2,11])$. Although we have found that $\mathrm{Cd}^{2}+(0.05 \mathrm{mM})$ considerably reduces the alkaline shift, in agreement with observations on the cerebellum [8], we cannot justify the conclusion that $\mathrm{Ca}^{2+}$ is involved. $\mathrm{Cd}^{2}+$ also reduced the conduction velocity, action potential amplitude and the stimulus-related release of potassium and acid, indicating an unspecific effect of $\mathrm{Cd}^{2+}$ on excitability rather than a specific action on the alkaline shift. An alternative possibility is that protons enter the fibres passively through voltage-sensitive channels opened during the action potentials.

Finally, we were concerned with the possible contribution of changes in extracellu$\operatorname{lar} \mathrm{pH}$ and $\mathrm{a} \mathrm{K}_{\mathrm{e}}$ to the activity-dependent excitability changes seen in the unmyelinated nerve fibres. In several experiments $\mathrm{pH}_{\mathrm{e}}$ and $a \mathrm{~K}_{\mathrm{e}}$ were passively changed in the bathing solution. The changes in latency of the $\mathrm{C}$-fibre potential were negligible compared with those evoked by stimulating the fibres (Fig. 3). This indicates again that the rise in the intracelllular $\mathrm{Na}^{+}$activity is the most important factor responsible for the stimulus-related decrease in conduction velocity.

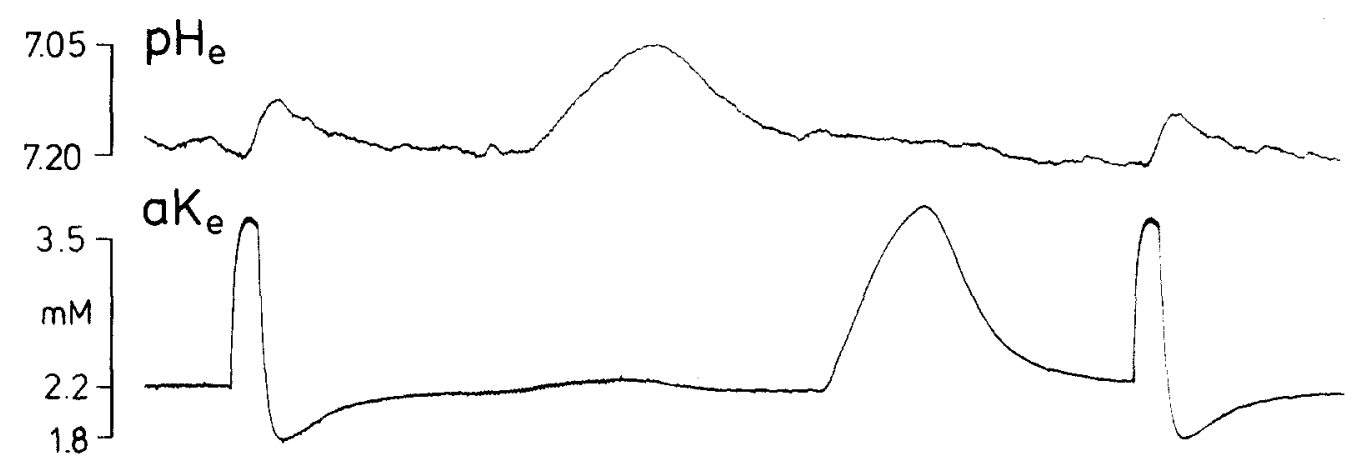

$\triangle$ latency

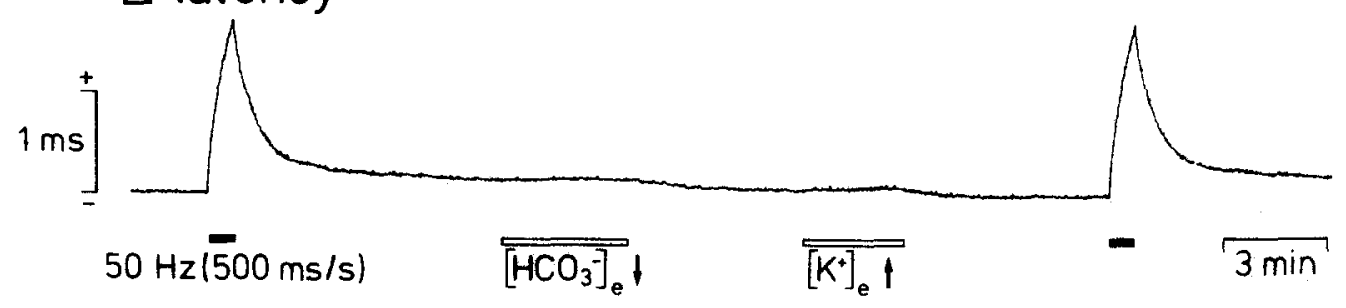

Fig. 3. Lack of importance of activity-related changes in the extracellular ionic environment for the excitability of the C-fibres. In this experiment, stimulus-related changes of $\mathrm{pH}_{\mathrm{e}}$ and $\mathrm{aK}_{\mathrm{c}}$ were compared with passive alterations of these parameters. At the beginning and end of the recording, intermittent stimulation was used as described in Fig. 1. Between the stimulation periods, firstly, the $\mathrm{HCO}_{3}^{-}$concentration in the bathing solution was lowered from 25 to $16 \mathrm{mM}$ at constant $\mathrm{pCO}_{2}$, and, secondly, the $\mathrm{K}+$ concentration was increased from 3 to $7 \mathrm{mM}$. 
This study was supported by the Wilhelm Sander Stiftung and the Medical Research Council. We would like to thank Mrs. C. Müller and Mrs. G. Schneider for technical and secretarial assistance.

1 Ammann, D., Lanter, F., Steiner, R.A., Schulthess, P., Shijo, Y. and Simon, W., Neutral carrier based hydrogen ion selective microelectrode for extra- and intracellular studies. Anal. (hem.. 53 (1981) 2267.2269

2 Baker. P.I.. Phosphorus metabolism of intact crab nerve and its relation to the active transport of ions, J. Physiol. (London), 180 (1965) 383423.

3 Ballanyi. K., Grafe, P. and ten Bruggencate, G., Intracellular free sodium and potassium, post-carbachol hyperpolarization, and extracellular potassium-undershoot in rat sympathetic neurones, Neurosci. Lett.. 38 (1983) 275279.

4 Bostock. 11. and Grafe. P.. Activity-dependent excitability changes in normal and demyelinated rat spinal root axons, J. Physiol. (London), 365 (1985) 239-257.

5 Förstl, J.. Galvan, M. and ten Bruggencate, G., Extracellular $\mathrm{K}^{+}$concentration during electrical stimulation of rat isolated sympathetic ganglia, vagus and optic nerves, Neuroscience, 7 (1982) 3221 -3229.

6 Gebert, G. and Friedman, S.M., An implantable glass electrode used for pH measurement in working skeletal muscle, J. Appl. Physiol., 34 (1973) 122 124.

7 Cirafe, P. Ballanyi, K. and ten Bruggencate, G., Changes of intracellular free concentrations, evoked by carbachol or GABA, in rat sympathetic neurons. In M. Kessler. D.K. Harrison and J. Höper (Eds.). Ion Measurements in Physiology and Medicine, Springer, Berlin. Heidelberg. New York. Tokyo. 1985. 184-188.

8 Kraig, R.P., Ferreira-Filho, C.R. and Nicholson, C., Alkaline and acid transients in cerebellar microenvironment, J. Neurophysiol., 49 (1983) 831-850.

9 Mutch, W.A.C. and Hansen. A.J., Extracellular $\mathrm{pH}$ changes during spreading depression and cerebral ischemia: mechanisms of brain $\mathrm{pH}$ regulation. J. Cereb. Blood Flow Metab., 4 (1984) 1727.

10 Ritchie, I.M. and Straub, R.W.. The hyperpolarization which follows activity in mammalian nonmedullated fibres. J. Physiol. (London), 136 (1957) 80-97.

11 Ritchie, J.M. and Straub, R.W., Phosphate efflux and oxygen consumption in small non-myelinated nerve fibres at rest and during activity, J. Physiol. (London), 287 (1979) 315-327.

12 Steinhagen, C., Hirche, H.J., Nestle, H.W., Bovenkamp, U. and Hosselmann, I., The interstitial pH of the working gastrocnemius muscle of the dog, Pflügers Arch., 367 (1976) 151-156.

13 Urbanics, R., Leninger-Follert, E. and Lübbers, D.W., Time course of changes of extracellular $H$ and $K$ activities during and after electrical stimulation of the brain cortex. Pflügers Arch., 378 (1978) 4753. 